\title{
DEFENSIVE ADAPTATIONS AND NATURAL ENEMIES OF A CASE-BEARING BEETLE, EXEMA CANADENSIS (COLEOPTERA: CHRYSOMELIDAE)
}

\author{
By Richard B. Root and Frank J. Messina* \\ Section of Ecology and Systematics, \\ Corson Laboratory, Cornell University \\ Ithaca, New York 14853, U.S.A.
}

\section{INTRODUCTION}

The larval habit of constructing and carrying a portable case has evolved many times in the Holometabola. It is a widespread trait of the Trichoptera and Lepidoptera (e.g. the Coleophoridae and Psychidae). Among the Coleoptera, casebearing is found in four related subfamilies of the Chrysomelidae, the so-called camptosomates: Clytrinae, Cryptocephalinae, Chlamisinae, and Lamprosomatinae (Böving and Craighead 1931). The larval case of many insects is thought to function primarily in defense by providing armor or camouflage (Otto and Svensson 1980). Here we describe the uses of the case and other defenses in a chlamisine beetle, Exema canadensis Pierce, and speculate briefly on the evolution and consequences of the case-bearing habit.

The genus Exema Lacordaire contains nine species in North America (Karren 1966). All of the species appear to be univoltine and to feed on a fairly restricted range of herbaceous or shrubby genera in the Asteraceae (Jenks 1940; Karren 1966, 1972). In central New York E. canadensis is commonly found on goldenrods (Solidago spp.) and asters (Aster spp.). Its life cycle was summarized by Messina and Root (1980). Le Sage (1982) recently described the immature stages.

\section{Methods}

We observed the life history and natural enemies of E. canadensis during 1979 and 1980 at Whipple Farm, 8 km N.E. of Ithaca, New

*Present address: Boyce Thompson Institute for Plant Research, Tower Road, Ithaca, New York 14853, U.S.A.

Manuscript received by the editor January' 24, 1983. 
York. Field-collected larvae and pupae were reared to measure the incidence of parasitoids. Voucher specimens of $E$. canadensis and its enemies were placed in the Cornell University Insect Collection (Lot no. 1068).

The morphology of E. canadensis was examined with the scanning electron microscope. Larval cases and adults were air-dried and mounted on metal stubs with double-sided tape. Larvae and pupae were dehydrated in an ethanol series and critical-point dried with $\mathrm{CO}_{2}$ before mounting. All specimens were sputter-coated with gold-palladium (ca. 200A). Measurements of larvae and cases were made with an ocular micrometer.

We did experiments on the protective functions of the case by exposing beetles to three predaceous insects: Podisus maculiventris (Say) (Pentatomidae), Nabicula subcoleoptrata (Kirby) (Nabidae), and Hippodamia glacialis (F.) (Coccinellidae). For these experiments we carefully extracted 4th-instar larvae from their cases; this procedure did not appear to harm the larvae. "Exposed" and untreated ("encased") larvae were placed in petri dishes containing moist filter paper and a few goldenrod leaves. In trials using $P$. maculiventris, two 5th-instar nymphs were taken from a vigorous lab culture and added to dishes containing three exposed and three encased E. canadensis larvae (a choice situation). We recorded the number of each prey type that were consumed by the stink bugs after 6 and 24 h. In trials using $N$. subcoleoptrata and $H$. glacialis, field-collected adults were starved for 24,48 , or $72 \mathrm{~h}$ before being added to dishes containing either exposed or encased $E$. canadensis larvae (a no-choice situation). Each dish held three predators and five prey. We recorded prey consumption hourly for up to $5 \mathrm{~h}$.

\section{RESULTS}

\section{The larval case and adaptations associated with its use}

In chlamisine beetles the female parent provides the initial larval case in the form of an egg case or "scatoshell" (Hinton 1981). The female deposits a single yellow egg that is attached to the plant on a smooth, yellowish stalk (Figs. 1-3) that appears to be continuous with the egg chorion. The attachment is shaped into the contours of the leaf or stem surface (Fig. 3), suggesting that the base of the stalk is extruded in a plastic state. The female then systematically surrounds the egg with strips of green fecal material. She starts around 

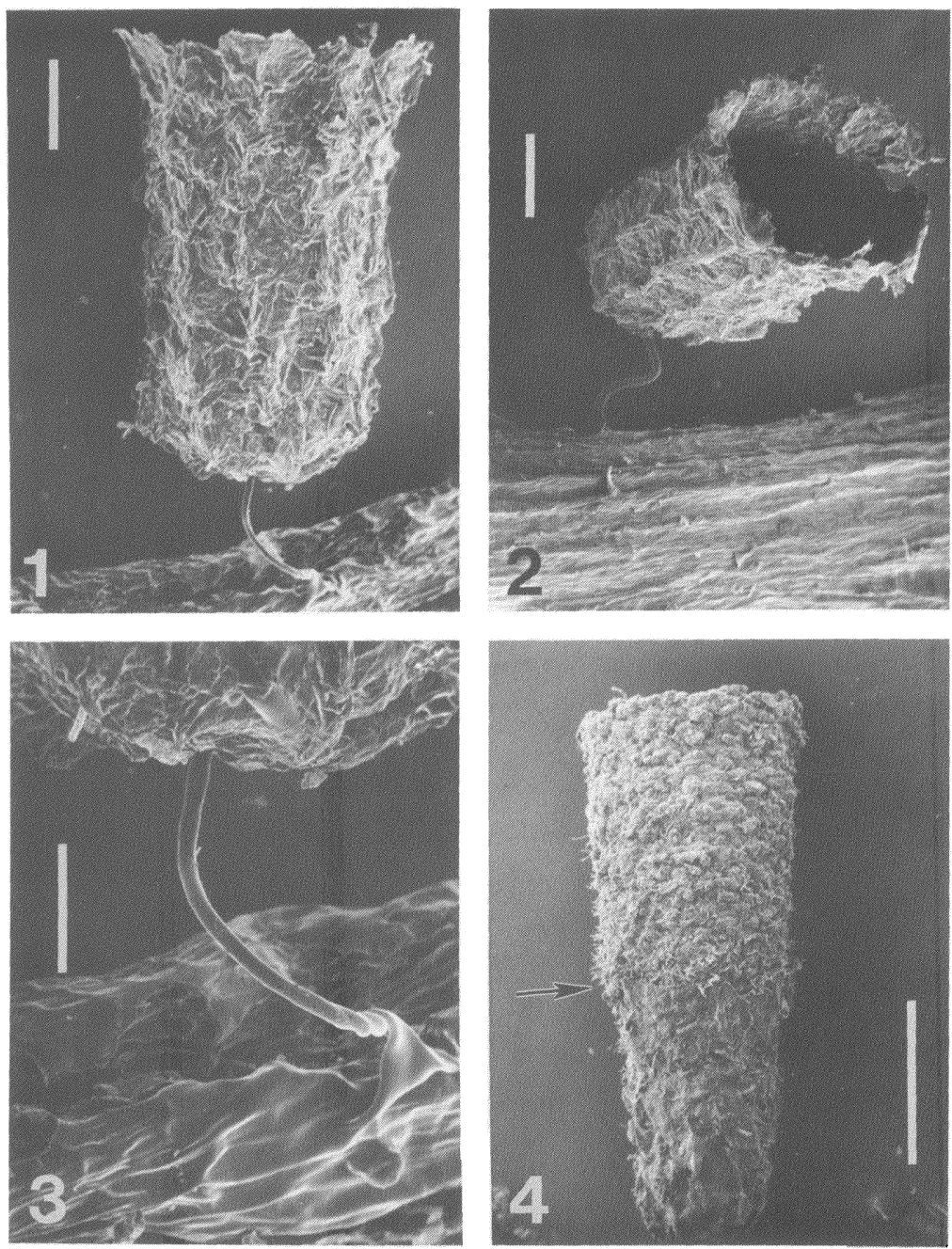

Figs. 1-4: Cases of E. canadensis. 1, Egg case with egg stalk attached to stem. 2. View from top of case before cap has been added (egg was removed). 3, Close-up of egg stalk and base. 4, Case of 1st instar larva. Arrow indicates juncture between original egg case and larval additions. Scale bars $=500$ (Fig. 4), 200 (Figs. 1-2), or 100 (Fig. 3) $\mu \mathrm{m}$. 
the stalk and periodically twists the egg with her hind legs as she builds up the sides until the egg is enclosed in a cuplike case with a flared ridge (Figs. 1-2). A flat top is then added to seal the egg in the case. The flexible egg stalk often remains twisted beneath the case (Fig. 3). The entire deposition process takes $20-30 \mathrm{~min}$ in the laboratory. The egg case turns a drab brown color as it dries.

The larva emerges by chewing through the flat top of the case. It then flips the case over, presumably after severing the connection with the egg stalk (Karren 1972). Inside the inverted egg case, the larva assumes the characteristic folded posture of the camptosomates with the mouth and anus both adjacent to the single case opening.

The larva begins to feed and gradually enlarges the case by adding its own fecal material to the rim around the opening. The juncture between the contributions of the mother and the larva remains distinct (Figs. 4-5), and the original egg case eventually appears as a small nipple projecting from the tail of the larval case. A larva passes through four stadia, always molting within the enlarging case (Le Sage 1982). Case length is a moderately good predictor of larval instar, as determined by the width of the head-capsule (Table 1).

Larvae of $E$. canadensis possess several morphological features that are probably related to the case-bearing habit. The legs are unusually long; each coxa is movable and so elongated that it exceeds the length of the femur (Fig. 6). The legs can extend laterally beyond the rim of the case when the larva is walking. If disturbed, the larva retracts its legs and pulls the case down so that the rim is appressed to the foliage (Wallace 1970). The strongly recurved tarsal claws (Fig. 7) may facilitate this maneuver by providing a firmer grip on the substrate. The larval cuticle, which is normally covered, is sclerotized in only a few areas (Le Sage 1982). Setae (usually tricoid sensillae) are sparse, but spiny or rounded protuberances are scattered over much of the surface. These protuberances serve may to increase traction between the larval cuticle and the case. The larval spiracles are uniforous and annular (Fig. 8). The requirements for spiracular closure and moisture retention may be reduced in a case-bearer; Karren (1964) reports that artificially exposed Exema larvae are highly vulnerable to desiccation.

The prepupa seals the case rim to a leaf or stem with a layer of frass. It then reorients itself so that the posterior end is against the 
Table 1: Head capsule widths and case lengths (in $\mathrm{mm}$ ) of the immature stages of E. canadensis.

\begin{tabular}{lccccc}
\hline & Egg & I & II & III & IV \\
\hline Head width & & & & & \\
$\overline{\mathbf{x}}(\mathrm{SE})$ & & $0.29( \pm .01)$ & $0.37( \pm .02)$ & $0.50( \pm .02)$ & $0.67( \pm .02)$ \\
$\mathrm{N}$ & & 7 & 7 & 7 & 9 \\
Case length' & & & & & \\
$\overline{\mathbf{x}}(\mathrm{SE})$ & $1.05( \pm .05)$ & $1.62( \pm .38)$ & $2.69( \pm .33)$ & $3.55( \pm .32)$ & $4.34( \pm .26)$ \\
$\mathrm{R}$ ange & $0.96-1.12$ & $1.04-2.32$ & $2.16-3.36$ & $2.80-4.08$ & $3.84-4.80$ \\
$\mathrm{~N}$ & 12 & 23 & 18 & 32 & 45 \\
\hline
\end{tabular}

'As measured from case opening to tip of original egg case.

substrate and the anterior end faces the nipple at the tail. Fully sclerotized adults cut a circular cap in the tail of the case with their mandibles; this cap is pushed off as the beetles emerge. The barrelshaped, tuberculate adults (Figs. 9-10) can be easily mistaken for caterpillar frass by humans (Jenks 1940; Karren 1964; and our personal experiences). It may be that vertebrate predators overlook them in the same way. The adults exhibit the widespread chrysomelid trait of quickly withdrawing the legs and dropping off the substrate when they are disturbed. This escape mechanism is elaborated in Exema; the deep sternal grooves (Fig. 10) allow the adult to retract its appendages so completely that the falling beetle bounces and rolls off the foliage. The compact adults also slide deeply into the litter beneath the plant and often come to rest in a deep recess where they are extremely difficult to find.

\section{Natural enemies}

No predators were seen to attack the larvae of E. canadensis during the many hours that we and our associates, E. W. Evans and J. A. Gowan, have spent observing the goldenrod fauna in the field. The three species of predaceous insects used in our experiments, however, were frequently observed to kill the larvae of other chrysomelid species that are associated with Solidago in central New York (Evans 1982; Messina 1982). In the laboratory, exposed $E$. canadensis larvae were readily captured and eaten by these predators (Table 2). In contrast, few encased larvae were consumed even though the confined space in the petri dishes must have increased 

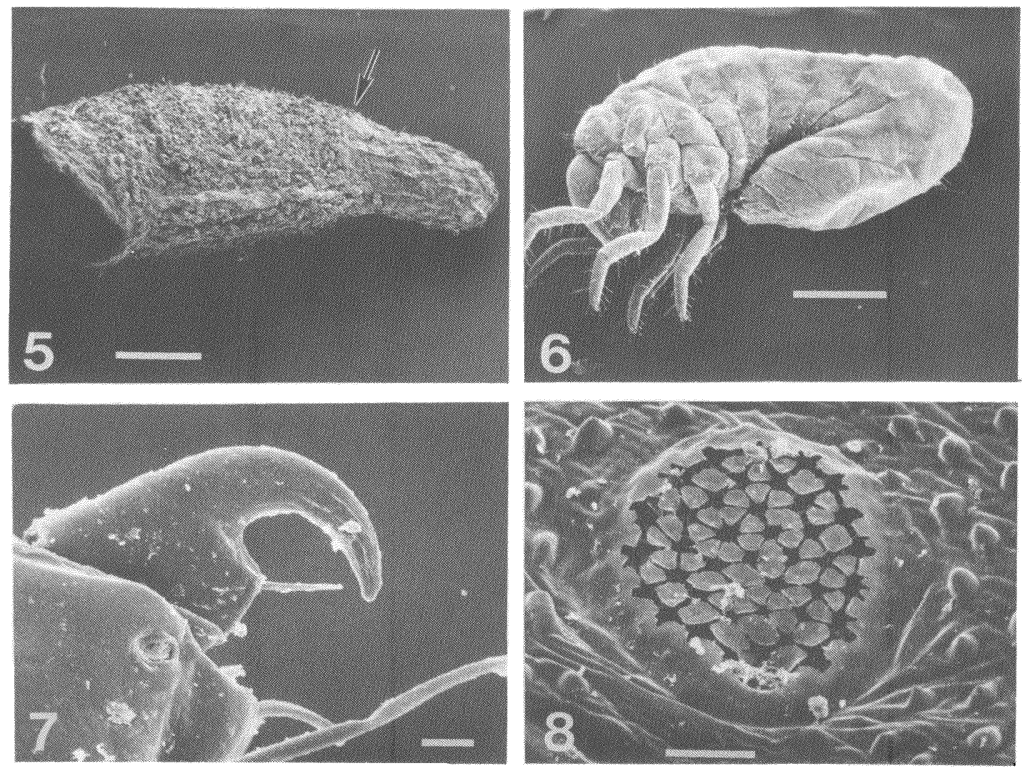

Figs. 5-8: Case and larval morphology of E. canadensis. 5, Case of 3rd instar larva. 6, 3rd instar larva, lateral view. 7, Tarsal claw. 8, 2nd abdominal spiracle. Arrow indicates juncture between original egg case and larval additions. Scale bars $=500$ (Figs. 5-6) or 10 (Figs. 7-8) $\mu \mathrm{m}$.

the frequency of encounter between predator and prey far above the usual conditions in nature. The coccinellid, $H$. glacialis, never succeeded in capturing an encased larva and nine of the ten encased prey consumed by the pentatomid, $P$. maculiventris, were taken only after all of the exposed larvae in the dish had been eaten. The rate that exposed larvae were consumed by $N$. subcoleptrata and $H$. glacialis was increased by starvation (Fig. 11).

The protective function of the larval case is further illustrated by its influence on predator behavior. The predator appeared to approach in response to prey movement with the outcome that attacks were launched, without apparent discrimination, on both exposed and encased larvae. Attacks on exposed larvae were quickly and invariably successful. Upon encountering an encased larva, the predators with sucking mouthparts $(N$. subcoleoptrata and $P$. maculiventris) touched the case with their forelegs and extended their beaks. They were never able to penetrate the case 

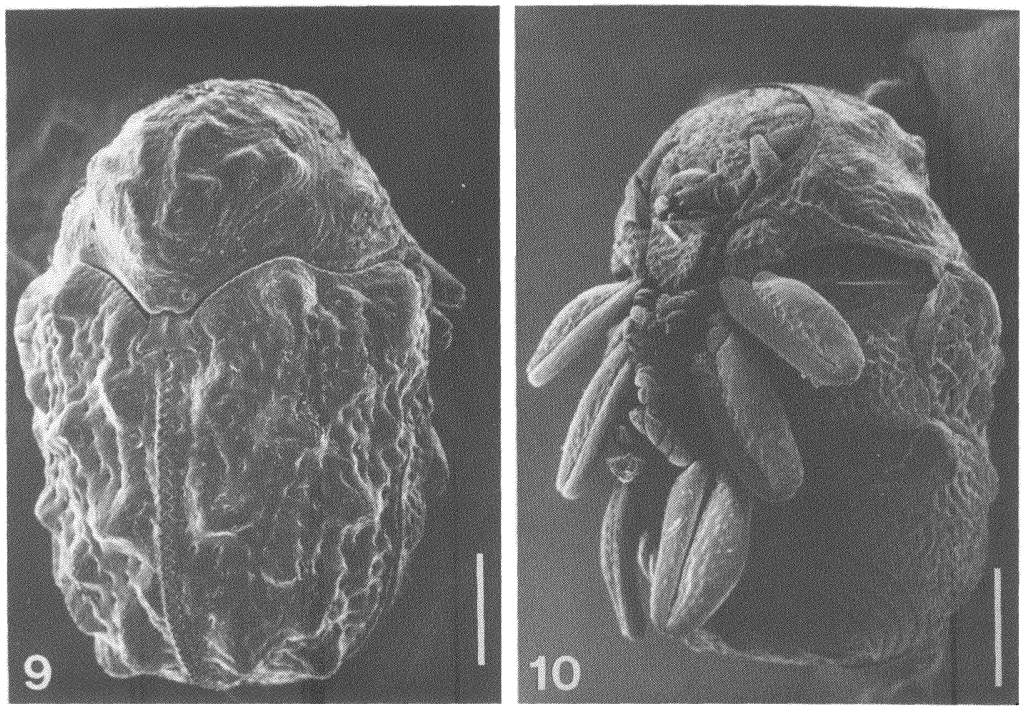

Figs. 9-10: Adult E. canadensis. 9, Dorsal view. 10, Ventral view. Scale bars $=500$ $\mu \mathrm{m}$.

even though they made repeated probes. In those instances when these hemipterans did consume encased prey, they fed through the case opening on the few occasions when a larva had been knocked on its side. This is an unlikely event in nature because dislodged larvae fall from the plant. The chewing predator, $H$. glacialis, attacked the encased larvae by attempting to insert the mandibles under the rim of the case; we never observed success in this endeavor.

The case is an ineffective barrier to certain adapted parasitoids. Larvae at both field sites were parasitized by a Tetrastichus sp. (Eulophidae); this was possibly $T$. chlamytis Ashmead, a species that is only known to attack chlamisine beetles (Burks 1979). Rates of parasitism ranged from 16 to $42 \%$ (Table 3). We obtained an average of 8.6 Tetrastichus adults/infested host (range, 5-14 wasps; $\mathrm{n}=\mathbf{3 7}$ hosts). Parasitoids emerged from larvae that were collected in the field as both early (I-II) and late (III-IV) instars. The cuticle of a parasitized larva turns from white to black and the host dies shortly before the time it would normally pupate. The wasps usually emerged from the case opening, but a small exit hole was observed 
Table 2: Consumption of exposed and encased larvae of E. canadensis by three arthropod predators in laboratory arenas.

\begin{tabular}{lcccc}
\hline \multicolumn{1}{c}{ \% available prey consumed } & & \\
& Exposed & Encased & $\mathrm{N}^{1}$ & P2 \\
\hline $\begin{array}{c}\text { Podisus maculiventris } \\
\text { nymphs }\end{array}$ & 69 & 19 & 54 & .001 \\
$\begin{array}{c}\text { Nabicula subcoleoptrata } \\
\text { adults }\end{array}$ & 70 & 7 & 30 & .001 \\
$\begin{array}{l}\text { Hippodamia glacialis } \\
\text { Pipor }\end{array}$ & 87 & 0 & 30 & .001 \\
\hline
\end{tabular}

'Number of each prey type offered.

2Chi-square test, where expected values assume equal consumption of each prey type.

in the case of a larva that had cemented the opening to the substrate before it died. We could not determine if Tetrastichus females oviposit through the case wall or under the rim. In the field, however, we commonly observed Tetrastichus adults that remained perched on the side of a larval case for prolonged periods. Perhaps these wasps were waiting for the larva to move and thus expose a vulnerable spot for oviposition.

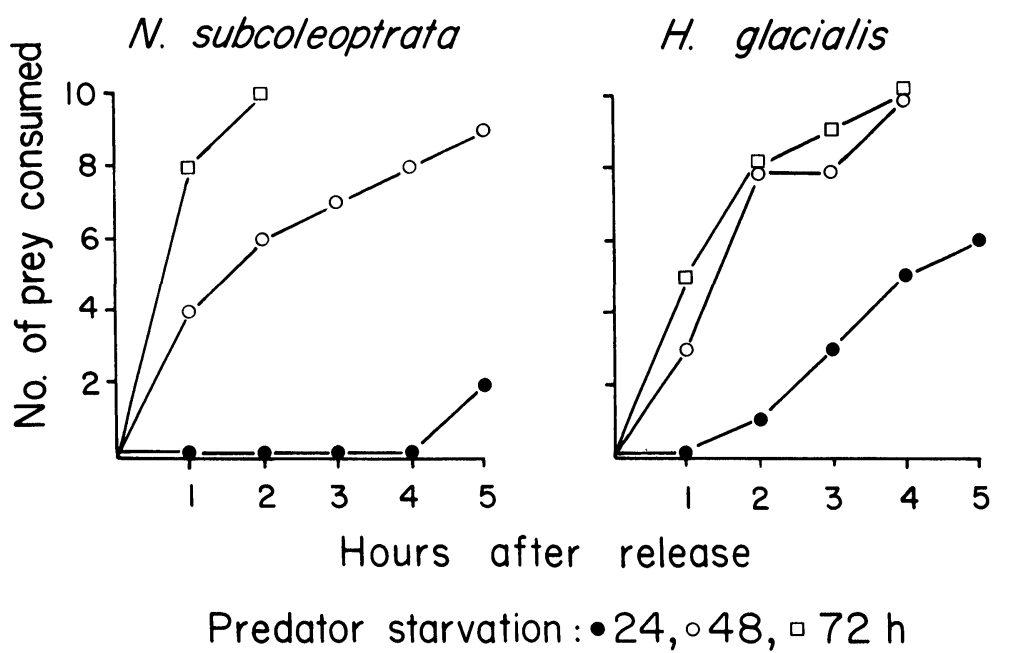

Fig. 11: Consumption of exposed E. c'anadensis larvae by Nabicula subcoleoptrata and Hippodamia glacialis in the laboratory. Predators were starved for 24-72 h before release. Ten prey were offered per trial. 
Six of 22 pupae that were collected on August 21, 1979, were parasitized by Spilochalcis albifrons (Walsh) (Chalcidae), a species that has previously been reported from Exema dispar Lacordaire (Burks 1979). One chalcid emerged from each host. No S. albifrons were found in $E$. canadensis that were collected as larvae. If this chalcid attacks only pupae, it must be able to oviposit through the case wall because the case rim is sealed to the substrate by the prepupae. In this regard, it is interesting to note that $S$. albifrons has been taken from a broad range of unrelated case-bearing and leafmining insects. Moreover, at least four of the seven species in the side group, to which $S$. albifrons belongs, parasitize case-bearing chlamisines and coleophorids (Burks 1979). These observations suggest that the evolution of specializations in Spilochalcis is more closely linked to the abilities required to penetrate materials that cover the host than it is to factors that are more narrowly associated with the host's taxonomic affinity.

Larval mermithid nematodes were found in dissections of a few field collected $E$. canadensis larvae. These parasites are functionally similar to parasitoids, killing the hosts as they exit the body following development (Nickle 1974).

Larvae of an erythraeid mite, Leptus sp., were found attached at several locations on beetles. In a survey done in late August 1979, $67 \%$ of the 43 adult beetles sampled bore at least one mite. There was an average of 1.7 mites on the infested beetles and as many as five mites were found on a single host. Nothing is known about the influence of these mites on the beetles.

Table 3: Per cent of E. canadensis larvae parasitized by a Tetrastichus sp. in 1979 and 1980. (Sample sizes in parentheses.)

\begin{tabular}{ccccc}
\hline Site & \multicolumn{4}{c}{ Collection date } \\
\hline Brooktondale 1979 & 3 July & 29 July & 21 August & 21 August ${ }^{\prime}$ \\
& $17(107)$ & 16(57) & $38(21)$ & $27(22)^{2}$ \\
Whipple Farm 1980 & 28 June & 1 July & 4 July & 16 July \\
& $23(61)$ & $42(19)$ & $40(55)$ & $31(13)$ \\
\hline
\end{tabular}

'These cases contained pupae; the larvae had cemented the case rim to the substrate prior to collection.

2An additional $27 \%$ of the pupae were parasitized by Spilochalcis albifrons. 


\section{Discussion}

The defensive adaptations of the immature and adult stages of $E$. canadensis are quite different even though they occur in the same microhabitats, overlap in their seasonal occurrences, and encounter similar predators. The cases that cover the eggs and larvae appear to deter most, if not all, of the several invertebrate predators that forage on goldenrods (see Messina 1982 for a list). Wallace (1970) has found that the case of another chlamisine, Neochlamisus gibbosus (F.) (= Anthrochlamys plicata $\mathrm{F}$.), protects the larvae from imported fire ants. The defenses of adult chlamisines require further investigation. Nevertheless, it seems obvious that a variety of escape mechanisms are derived from the adults' morphology. As a consequence of their hard, compact body form, adults are well-armored against the initial thrusts of predators and they are more likely to tumble into a refuge after dropping from the foliage. Furthermore, because of their resemblance to caterpillar frass, adults may be overlooked by many predators that rely on vision (Jenks 1940).

Many chrysomelids are chemically defended against predators (e.g. Meinwald et al. 1977; Howard et al. 1982). Adults in the camptosomate group, however, lack the defense glands found in most chrysomelid subfamilies (Deroe and Pasteels 1982). This suggests that chlamisine adults must rely primarily on the mechanical and behavioral defenses discussed above.

The major enemies of $E$. canadensis are the parasitoids, $S$. albifrons and $T$. chlamytis. Specialized parasitoids have been highly successful in overcoming most of the defenses (e.g. reflex bleeding, fecal shields, glandular secretions) employed by chrysomelid larvae to deter predators (Eisner et al. 1967; Wallace 1970; Matsuda and Sugawara 1980).

Several characteristics of E. canadensis can be grouped into an adaptive syndrome that is associated with the case-bearing habit. This coordinated set of traits includes the bowed posture, long legs, and other morphological adaptations that accommodate the larvae to life within the confinement of a case. In addition, casebearing probably influences other aspects of the natural history. For instance, the time and case-building material that the female must invest in each egg may result in a lowered reproductive rate. We observed that 30 females laid an average of only 1.2 eggs per day over a six-day period; Karren (1972) reports similar oviposition 
rates. This low output is reflected in the females' reproductive morphology. In dissections we found that females of E. canadensis have only four or five ovarioles per ovary and that each ovary never contains more than one fully mature öocyte. Camptosomate beetles, in general, have relatively few ovarioles per ovary (Robertson 1961; Suzuki 1974; Mann and Singh 1979). Beetles may compensate for gradual egg production by ovipositing over an extended period. In central New York, overwintered females begin egg-laying in early May and continue until mid-July.

The low fecundity of $E$. canadensis may be related to its normally low and relatively stable population size. Over a three-year period, the population densities of five other chrysomelid species that feed on goldenrod fluctuated by at least an order of magnitude (Messina and Root 1980). During this same period the population of E. canadensis varied less than twofold. Furthermore, during the course of our long-term investigations on the goldenrod fauna at several localities in central New York, we have yet to observe a host plant that was significantly depleted by E. canadensis. Karren (1964) has also noted the stable densities of Exema populations. Le Sage (1982), however, reported that during 1980-81, populations of $E$. canadensis increased greatly over a large area in southern Canada.

The evolutionary steps that produced the case-bearing habit are unclear. Since the larval case is added to the egg case, it can be argued that the defense originated with the female's habit of covering the eggs with fecal material (this may be mixed with secretions from the anal gland; Hinton 1981). This initial step is exhibited by other chrysomelids, e.g. the eumolpine, Chrysochus auratus (Fabricius). The extant species of camptosomate beetles differ in their manner of oviposition and egg case deposition. Some clytrine beetles lay eggs in clusters (a typical trait of non-camptosomate chrysomelids), with each egg connected to the substrate by a separate stalk (Hinton 1981). A cryptocephaline, Pachybrachis bivittatus (Say), apparently does not connect the egg to the substrate at all. Instead, the female covers the egg with fecal material while holding it with her hind legs, and then simply drops the egg to the ground (Lawson 1976). Further comparative data on the details of egg-case provisioning are needed to trace further the evolution of the casebearing habit and the often enigmatic phylogeny of the camptosomate line (Mann and Crowson 1981). 


\section{ACKNOWLEDGEMENTS}

We thank E. W. Evans and M. K. Hausmann for technical assistance. N. F. Johnson and B. M. O'Connor identified the parasitoids and mites respectively. The research was supported by NSF grant DEB77-25120.

\section{SUMMARY}

Morphological and behavioral defenses of Exema canadensis are illustrated with scanning electron micrographs. In laboratory experiments, the fecal case was shown to protect larvae from three predaceous insects (a nabid, a pentatomid, and a coccinellid) that occur in the same microhabitats with $E$. canadensis. Exposed larvae were readily consumed by predators. The case did not deter parasitoids; larvae were heavily parasitized by a eulophid, Tetrastichus sp., and pupae were attacked by a chalcid, Spilochalcis albifrons. Other enemies include mermithid nematodes and erythraeid mites. The adaptive syndrome associated with the case-bearing habit and its possible evolution are discussed.

Böving, A. G. and F. C. Craighead

\section{Literature Cited}

1931. An illustrated synopsis of the principal larval forms of the order Coleoptera. Entomol. Amer. 11: 1-351.

BuRKs, B. D.

1979. Chalcididae, pp. 860-873 and Eulophidae, pp. 967-1021. In K. V. Krombein, P. D. Hurd, Jr., O. R. Smith, and B. D. Burks (eds.), Catalog of Hymenoptera in America north of Mexico. Washington, D.C., Smithsonian Institution Press.

Deroe, C. and J. M. Pasteels

1982. Distribution of adult defense glands in chrysomelids (Coleoptera: Chrysomelidae) and its significance in the evolution of defense mechanisms within the family. J. Chem. Ecol. 8: 67-82.

Eisner, T., E. Van Tassell, and J. E. Carrel

1967. Defensive use of a "fecal shield" by a beetle larva. Science 158: 1471-1473.

Evans, E. W.

1982. Feeding specialization in predatory insects: hunting and attack behavior of two stinkbug species (Hemiptera: Pentatomidae). Amer. Midl. Nat. 108: $96-104$.

HinTON, H. E.

1981. Biology of insect eggs, vol. II. Oxford, Pergamon Presss. 778 pp. 
Howard, D. F., M. S. Blum, T. H. Jones, and D. W. Phillips

1982. Defensive adaptations of eggs and adults of Gastrophy'sa cyanea (Coleoptera: Chrysomelidae). J. Chem. Ecol. 8: 453-462.

JENKS, G. E.

1940. Dwarfs that live in their hats. Nature Mag., pp. 337-340.

KARREN, J. B.

1964. Protective coloration and form in the North American genus Exema (Chrysomelidae, Coleoptera). Proc. North Central Branch, Entomol. Soc. Amer. 19: 77-79.

1966. A revision of the genus Exema of America, north of Mexico (Chrysomelidae, Coleoptera). Univ. Kansas Sci. Bull. 46: 647-695.

1972. A revision of the subfamily Chlamisinae of America north of Mexico (Coleoptera: Chrysomelidae). Univ. Kansas Sci. Bull. 49: 875E988.

LAWSON, F. A.

1976. Egg and larval case formation by Pachybrachis bivittatus. Ann. Entomol. Soc. Amer. 69: 942-944.

Le SAge, L.

1982. The immature stages of Exema canadensis Pierce (Coleoptera: Chrysomelidae). Coleop. Bull. 36: 318-327.

Mann, J. S. and R. A. Crowson

1981. The systematic positions of Orsodacne Latr. and Syneta Lac. (Coleoptera, Chrysomelidae), in relation to characters of larvae, internal anatomy and tarsal vestiture. J. Nat. Hist. 15: 727-749.

MANN, J. S. AND J. B. Singh

1979. Ovariole number in the family Chrysomelidae (Coleoptera: Polyphaga) from northern India. J. Entomol. Res. 3: 217-222.

Matsuda, K. and F. Sugawara

1980. Defensive secretion of chrysomelid larvae Chrysomela vigintipunctata costella (Marseul), C. populi L., and Gastrolina depressa Baly (Coleoptera: Chrysomelidae). Appl. Entomol. Zool. 15: 316-320.

Meinwald, J., T. H. Jones, T. Eisner, and K. Hicks

1977. New methylcyclopentanoid terpenes from the larval defensive secretion of a chrysomelid beetle (Plagiodera versicolora). Proc. Nat. Acad. Sci. U.S.A. 74: 2189-2193.

Messina, F. J.

1982. Comparative biology of the goldenrod leaf beetles, Trirhabda virgata Le Conte and T. horealis Blake (Coleoptera: Chrysomelidae). Coelop. Bull. 36: $255-269$.

Messina, F. J. and R. B. Root

1980. Association between leaf beetles and meadow goldenrods. (Solidago spp.) in central New York. Ann. Entomol. Soc. Amer. 73: 641-646.

NickLE, W. R.

1974. Nematode infections, pp. 327-376. In G. E. Cantwell (ed.), Insect diseases, vol. II. New York, Marcel Dekker.

OtTo, C. AND B. S. Svensson

1980. The significance of case material selection for the survival of caddis larvae. J. Anim. Ecol. 49: 855-865. 
ROBERTSON, J. G.

1961. Ovariole numbers in Coleoptera. Can. J. Zool. 39: 245-263.

SuZIKI, K.

1974. Ovariole number in the family Chrysomelidae. J. Coll. Lib. Arts, Toyama Univ. 7: 53-70.

Wallace, J. B.

1970. The defensive function of a case on a chrysomelid larva. J. Georgia Entomol. Soc. 5: 19-24. 

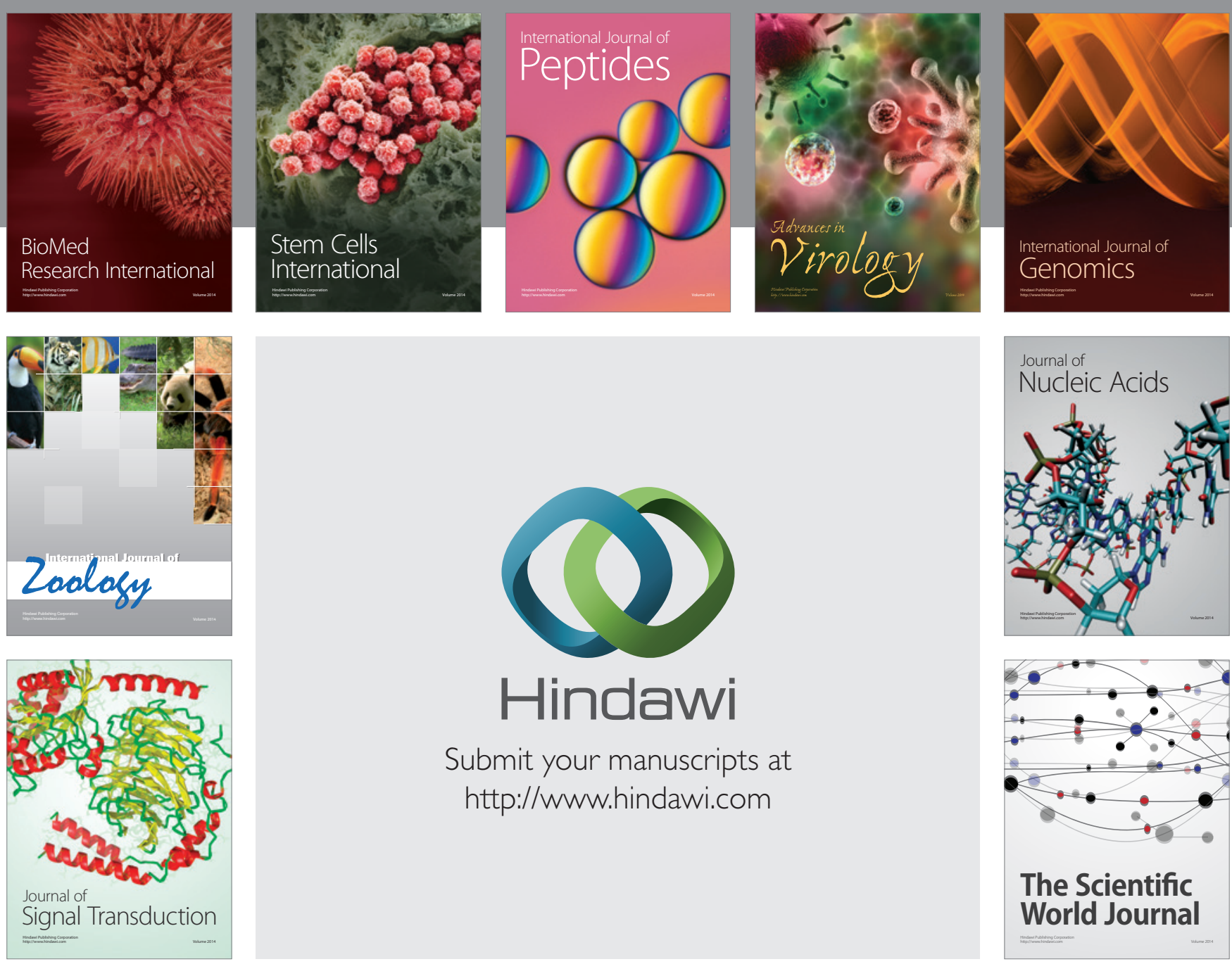

Submit your manuscripts at

http://www.hindawi.com
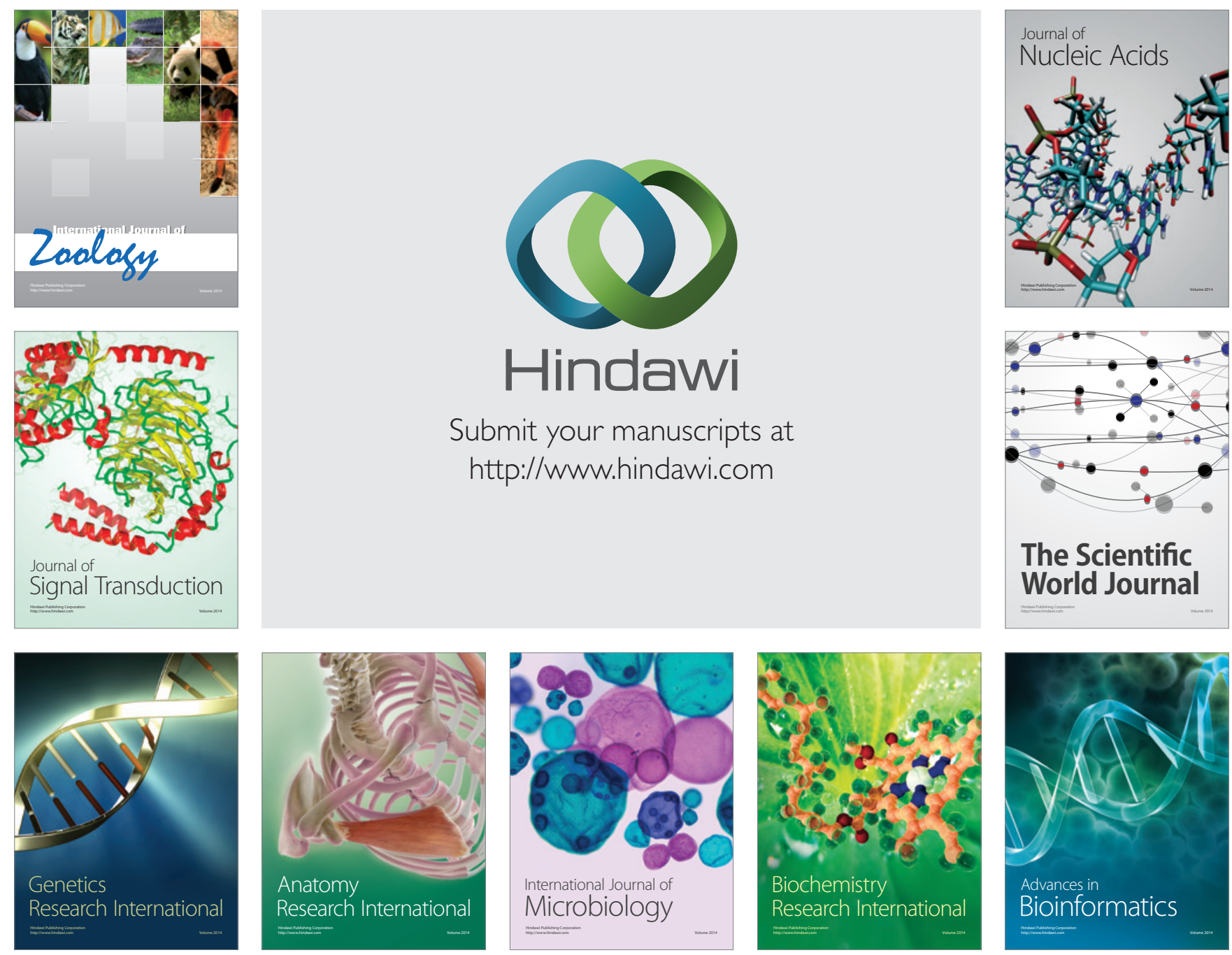

The Scientific World Journal
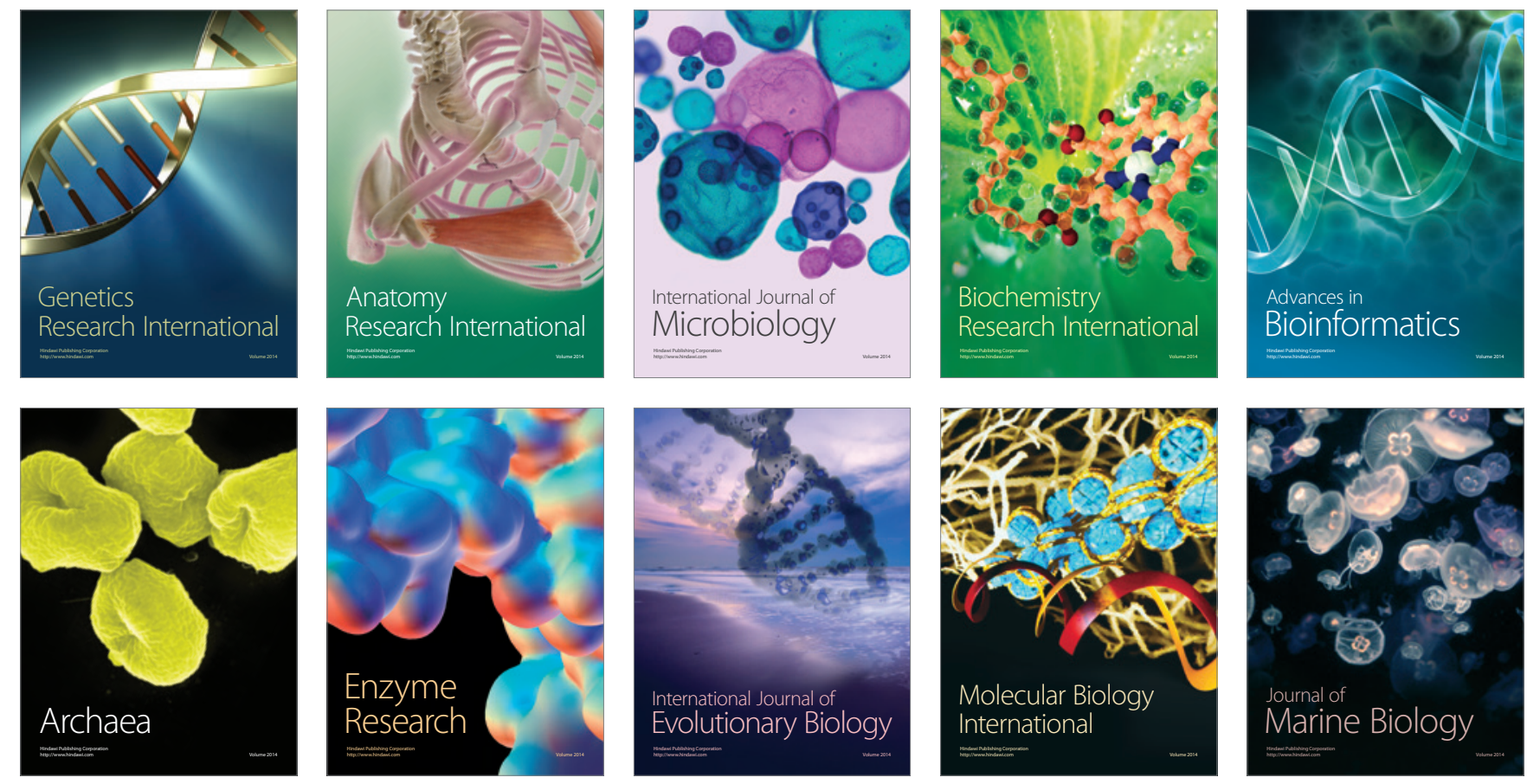